\title{
Gefitinib Plus Bevacizumab vs. Gefitinib Alone for $E G F R$ Mutant Non-squamous Non-small Cell Lung Cancer
}

\author{
CHIYOE KITAGAWA ${ }^{1}$, MASAHIDE MORI ${ }^{2}$, MASAO ICHIKI ${ }^{3}$, \\ NORIAKI SUKOH ${ }^{4}$, AKIKO KADA ${ }^{5}$, AKIKO M. SAITO ${ }^{5}$ and YUKITO ICHINOSE 6 \\ ${ }^{1}$ Department of Respiratory Medicine, National Hospital Organization Nagoya Medical Center, Nagoya, Japan; \\ ${ }^{2}$ Department of Thoracic Oncology, National Hospital Organization Toneyama National Hospital, Toyonaka, Japan; \\ ${ }^{3}$ Department of Respiratory Medicine, National Hospital Organization Kyushu Medical Center, Fukuoka, Japan; \\ ${ }^{4}$ Department of Respiratory Medicine, National Hospital Organization Hokkaido Medical Center, Sapporo, Japan; \\ ${ }^{5}$ Clinical Research Center, National Hospital Organization Nagoya Medical Center, Nagoya, Japan; \\ ${ }^{6}$ Department of Thoracic Oncology, National Hospital Organization Kyushu Cancer Center, Fukuoka, Japan
}

\begin{abstract}
Background/Aim: A phase II trial was conducted to assess the efficacy and safety of gefitinib plus bevacizumab for EGFR mutation-positive non-small cell lung cancer (NSCLC). Patients and Methods: Patients were randomly assigned to receive either gefitinib at $250 \mathrm{mg} /$ day alone or with bevacizumab at $15 \mathrm{mg} / \mathrm{kg}$ every 3 weeks. Results: Ten patients were allocated to the gefitinib group (group A) and 6 to the gefitinib plus bevacizumab group (group B). Median survival time (80\%CI) for progression-free survival (PFS) was 15.1 months for group $A$, and 5.4 months for group B. Overall survival probability at 1 year $(95 \%$ CI) was 0.750 for group $A$, and 0.667 for group $B$. The response rate was $44 \%$ for group $A$ and $50 \%$ for group $B$. Adverse events occurred at a similar frequency in both groups. Conclusion: PFS was shorter in group B than group A, and therefore there was no basis to proceed to a phase III trial.
\end{abstract}

Lung cancer is a leading cause of death worldwide ranking fifth (more than 1.6 million; 3.0\%) in the total number of deaths in 2015 (1). In Japan, lung cancer accounts for 19.9\% of cancer-related deaths and is the leading cause of death from malignant tumors. The annual number of lung cancer deaths in 2014 was approximately 73,000 ; therefore, improvements in treatment outcomes are an important issue (2).

This article is freely accessible online.

Correspondence to: Chiyoe Kitagawa, MD, Ph.D., Department of Respiratory Medicine, National Hospital Organization Nagoya Medical Center, 4-1-1, Sannomaru, Naka-ku, Nagoya, Aichi 4600001, Japan. Tel: +81 529511111, Fax: +81 529713334, e-mail: kitagawc@nnh.hosp.go.jp

Key Words: NSCLC, EGFR-TKI, VEGF inhibitor, gefitinib, bevacizumab.
Non-small cell lung cancer (NSCLC) accounts for $80-85 \%$ of all lung cancers, $60-70 \%$ of which are cases of stage IIIB/IV that are not indicated for surgery or definitive radiation therapy. The standard initial treatment for these cases is mainly based on combination chemotherapy including platinum anticancer drugs; however, the median survival following this treatment is only 8 to 10 months. Therefore, improving the treatment outcomes of advanced lung cancer, namely, those of chemotherapy, is essential.

EGFR tyrosine kinase inhibitors (EGFR-TKI) suppress EGFR signalling by binding to the ATP-binding site of the intracellular tyrosine kinase and inhibiting the autophosphorylation of EGFR. Gefitinib, erlotinib, afatinib and osimertinib are the currently approved EGFR-TKI in Japan.

EGFR gene mutations were reported in NSCLC in 2004, and a relationship was suggested to exist between the presence or absence of $E G F R$ gene mutations and the effects of EGFR-TKI (3-5). Subsequent studies reported that EGFR gene mutations comprised exon 19 deletions (44\%), L858R (41\%), and other mutations (approximately 15\%), including G719X and rare mutations such as exon 18-21 mutations in the tyrosine kinase domain (6).

In several phase III studies, EGFR-TKI have been shown to prolong progression-free survival (PFS) compared to platinum-based doublet chemotherapy in patients with EGFR mutation-positive NSCLC (7-9). In Japan, a significant elongation in progression-free survival (PFS) was shown in the gefitinib groups in a phase III study comparing gefitinib, carboplatin (CBDCA), and paclitaxel (PTX) [the NEJ002 study (8)] and in a phase III study comparing gefitinib $v s$. CDDP + docetaxel (DTX) [the WJTOG3405 study (9)] (the NEJ 002 study; HR=0.30, gefitinib group; 10.8 months, CBDCA + PTX group; 5.4 months, the WJTOG 3405 study; $\mathrm{HR}=0.520$, gefitinib group; 9.6 months, CDDP + DTX group; 6.6 months). However, no significant differences in overall 
survival (OS) were observed in these studies. This was attributed to the crossover to EGFR-TKI being performed at a very high rate post-treatment in the platinum combination group. The median survival time was reported to be 30.5 months in the gefitinib group and 23.6 months in the CBDCA + PTX group in the NEJ 002 study, and 35.5 months in the gefitinib group and 38.8 months in the CDDP + DTX group in the WJTOG 3405 study. Comparative phase III studies on erlotinib and platinum combination therapy in the same populations [the EURTAC study (10) and OPTIMAL study (11)] reported similar outcomes. EGFR-TKI are regarded as key drugs in EGFR gene mutation-positive cases. Since further improvements in treatment outcomes are required, the concomitant use of EGFR-TKI and other antineoplastic agents is considered. A previous study using a preclinical mouse model reported that gefitinib plus bevacizumab combination therapy was effective for EGFR gene mutationpositive lung cancer tumors with gefitinib resistance (12). Furthermore, the tumor interstitial EGFR signal has been reported to play a role in the resistance to bevacizumab, and the combination of EGFR-TKI plus bevacizumab has been suggested to inhibit angiogenesis (13). Some clinical trials have investigated the usefulness of the combination of erlotinib and bevacizumab in NSCLC patients (14-16). One of these studies on patients with activating EGFR gene mutations showed excellent outcomes. In the JO25567 study, median PFS was 16.0 months $(95 \% \mathrm{CI}=13.9-18.1)$ in patients with activating $E G F R$ gene mutations treated with erlotinib plus bevacizumab and 9.7 months $(95 \% \mathrm{CI}=5.7-11.1$ months) in those treated with erlotinib only (hazard ratio $=0.54$, 95\% CI=0.36-0.79, Log-rank test $p=0.0015)$ (14).

Currently, EGFR-TKI are the standard initial treatment for patients with EGFR mutation-positive NSCLC, and gefitinib monotherapy is widely used in Japan. The toxicity profile of gefitinib is similar to that of erlotinib, while the incidence of eruption and diarrhea is generally lower than that of erlotinib. In a Japanese randomized phase III trial comparing gefitinib with erlotinib, the gefitinib arm showed a tendency towards a significantly lower toxicity than the erlotinib arm (17). Therefore, the aim of this phase II trial was to evaluate the efficacy and safety of bevacizumab and gefitinib at normal dose settings.

\section{Patients and Methods}

This was an open-label, randomized, multicenter, phase II study. Primary eligibility criteria were pathologically proven nonsquamous NSCLC with stage IIIB/IV or recurrence, harboring activating EGFR mutations (exon 19 deletion or L858R), Eastern Cooperative Oncology Group performance status 0 to 2, age 20 years old or older, adequate hematological, hepatic, and renal function, measurable lesions, and a lifetime expectancy of more than 3 months. No prior chemotherapy for advanced disease was needed; however, previous postoperative adjuvant therapy of 6
Table I. Baseline characteristics.

\begin{tabular}{|c|c|c|}
\hline Characteristic & $\begin{array}{c}\mathrm{A} \\
(\mathrm{N}=10)\end{array}$ & $\begin{array}{c}\mathrm{B} \\
(\mathrm{N}=6)\end{array}$ \\
\hline \multicolumn{3}{|l|}{ Age (yr) } \\
\hline Median (range) & $72.5(66-82)$ & $73.5(68-79)$ \\
\hline \multicolumn{3}{|l|}{ Gender } \\
\hline Male & 3 & 1 \\
\hline Female & 7 & 5 \\
\hline \multicolumn{3}{|l|}{ Smoking history } \\
\hline Never smoked & 8 & 4 \\
\hline Former smoker & 2 & 2 \\
\hline \multicolumn{3}{|l|}{ Performance status } \\
\hline 0 & 7 & 2 \\
\hline 1 & 3 & 4 \\
\hline \multicolumn{3}{|l|}{ Histologic feature of tumor } \\
\hline Adenocarcinoma & 9 & 6 \\
\hline Other & 1 & 0 \\
\hline \multicolumn{3}{|l|}{ Disease stage at entry } \\
\hline IV & 9 & 6 \\
\hline Postoperative recurrence & 1 & 0 \\
\hline \multicolumn{3}{|l|}{$E G F R$ mutation } \\
\hline Exon 19 deletion & 6 & 4 \\
\hline Exon 21 L858R & 3 & 2 \\
\hline Other ${ }^{\#}$ & 1 & 0 \\
\hline \multicolumn{3}{|l|}{ History of chemotherapy } \\
\hline No & 10 & 6 \\
\hline
\end{tabular}

"Neither exon 19 deletion nor exon 21 L858R.

months or more was allowed. Primary exclusion criteria were confirmation of the T790M mutation, the presence of brain metastases, history or the presence of hemoptysis or bloody sputum, any coagulation disorder, tumors invading or abutting major blood vessels, the coexistence or history of interstitial lung disease, and active concomitant malignancy. This study was conducted in accordance with the Declaration of Helsinki and Good Clinical Practice guidelines. The study protocol was reviewed and approved by the Institutional Review Board of the National Hospital Organization or the individual Institutional Review Boards, and written informed consent was obtained from all patients.

This trial is registered in the UMIN Clinical Trials Registry (URL: http://www.umin.ac.jp/ctr/, UMIN000013586).

Randomization was performed by the minimization method using sex (male/female) and clinical stages (stage IIIB, postoperative relapse/stage IV) as allocation-adjusting factors. The analysis used a modified intention-to-treat approach, including all patients who received at least one dose of the study drug and had a tumor assessment at least once after randomization.

Patients received gefitinib alone at a dose of $250 \mathrm{mg} /$ day (group A) or with $15 \mathrm{mg} / \mathrm{kg}$ bevacizumab every three weeks (group B) as first-line therapy until disease progression or intolerable toxicity was confirmed. Dose reductions were not allowed for gefitinib or bevacizumab. Patients who required suspension of gefitinib for more than three weeks consecutively or of bevacizumab for more than six weeks from the date of the previous administration were discontinued from the study. 


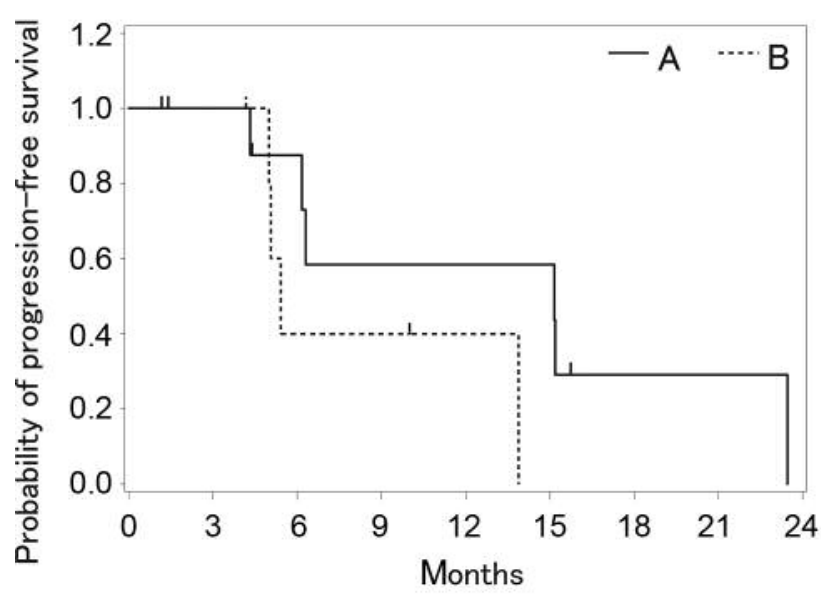

Figure 1. Kaplan-Meier curve of PFS for gefitinib alone (group A) and gefitinib plus bevacizumab (group B).

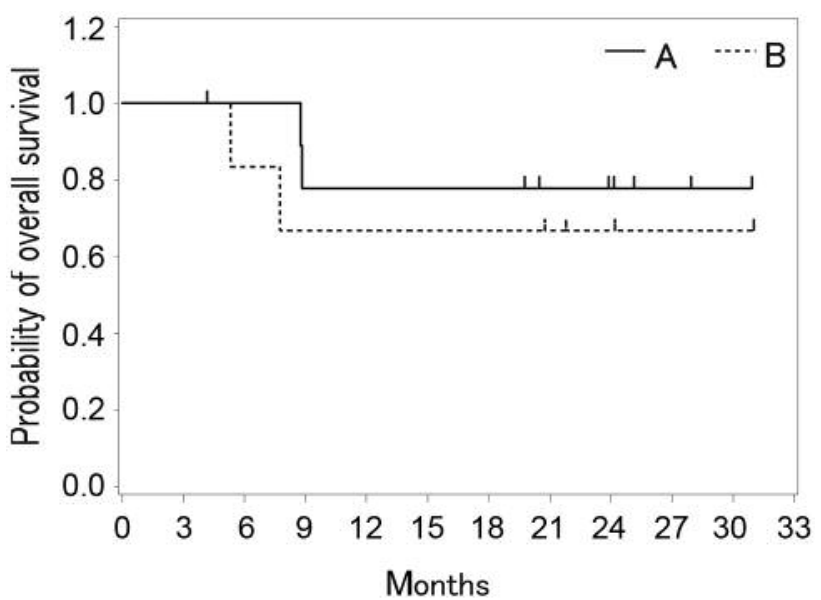

Figure 2. Kaplan-Meier curve of OS for gefitinib alone (group A) and gefitinib plus bevacizumab (group B).
Tumor lesions were assessed radiologically at baseline, every six weeks from week 1 to 18 months, and every 12 weeks thereafter until disease progression was confirmed according to RECIST 1.1 .

Adverse events were monitored and graded according to the National Cancer Institute Common Terminology Criteria for Adverse Events (CTCAE) version 4.0.

The primary endpoint was PFS, which was assessed by the attending physician. Secondary endpoints were overall survival (OS), response rate [the proportion of patients with complete response (CR) or partial response (PR)] and disease control rate [the proportion of patients with $\mathrm{CR}, \mathrm{PR}$, or stable disease (SD)] in the best objective response according to RECIST 1.1, and adverse events by CTCAE ver. 4.0.

Based on the findings of previous clinical studies, median PFS in gefitinib-treated patients was approximately ten months (4-6). Furthermore, a subset analysis of a small number of patients receiving a combination therapy with bevacizumab and EGFRTKI showed a median PFS of approximately 17 months $(9,10)$. Based on the median PFS in the gefitinib and gefitinib plus bevacizumab groups being 10 and 17 months, respectively, the number of patients required was calculated to be 42 per group under the following conditions: one-sided significance level of 0.1 , the statistical power of 0.80 , registration period of 24 months, and follow-up period of 18 months. Therefore, we set the total number of patients as 90 (45 per group) in consideration of dropouts.

The survival curves for PFS and OS were plotted using the Kaplan-Meier method. Compliance to gefitinib was calculated by dividing the number of days when gefitinib was actually taken by the prescribed number of days. Compliance to bevacizumab was calculated by dividing the number of cycles when bevacizumab was actually taken by the prescribed number of cycles.

All statistical analyses were performed using SAS software, version 9.4 (SAS Institute Inc., Cary, NC, USA).

\section{Results}

Sixteen patients from 10 centers in Japan were enrolled in this study between July 2014 and December 2015. The study ended earlier because of slow accrual.

Ten patients were allocated to group A and 6 to group B. The baseline characteristics of patients were similar between the two groups (Table I).

Since only patients with an exon 19 deletion or an exon 21 L858R mutation on the EGFR gene were eligible for this study, patients with other EGFR mutations were excluded from the full analysis set. Median survival time for PFS was $15.1(80 \% \mathrm{CI}=6.2-23.5)$ months for group $\mathrm{A}$, and 5.4 (5.013.9) months for group B (Figure 1).

OS probability at 1 year was $0.750(95 \% \mathrm{CI}=0.315-0.931)$ for group A, and $0.667(95 \% \mathrm{CI}=0.195-0.904)$ for group B (Figure 2).

The response rate was $44 \%$ (4/9) for group A and 50\% (3/6) for group B. The disease control rate was $100 \%$ for both groups.

The most common adverse events of any grades in group A were rash, increases in aspartate aminotransferase, alanine aminotransferase, and creatinine, and diarrhea. The most common adverse events of grade 3 or more in group A were increases in aspartate aminotransferase and alanine aminotransferase. An increase in alanine aminotransferase and diarrhea presented in two separate cases in group A were reported as serious adverse events. The former was recovered and the later was relieved.

The most common adverse events of any grade in group B were proteinuria, hypertension, rash, hematuria, hypoalbuminemia, and anorexia. The most common adverse 
Table II. Adverse events.

\begin{tabular}{|c|c|c|c|c|c|}
\hline \multirow[b]{2}{*}{ Adverse event } & & \multicolumn{2}{|c|}{$\begin{array}{c}\text { A }(\mathrm{N}=10) \\
\text { CTC grade }\end{array}$} & \multicolumn{2}{|c|}{$\begin{array}{c}\mathrm{B}(\mathrm{N}=6) \\
\text { CTC grade }\end{array}$} \\
\hline & & 1 or 2 & 3 & 1 or 2 & 3 \\
\hline \multirow[t]{7}{*}{ Investigations } & Alanine aminotransferase increased & 2 & 3 & 0 & 2 \\
\hline & Aspartate aminotransferase increased & 3 & 3 & 1 & 0 \\
\hline & Blood bilirubin increased & 1 & 0 & 0 & 0 \\
\hline & Creatinine increased & 4 & 0 & 1 & 0 \\
\hline & Investigations & 1 & 0 & 0 & 0 \\
\hline & Platelet count decreased & 0 & 0 & 1 & 0 \\
\hline & Weight loss & 1 & 0 & 0 & 0 \\
\hline \multirow{2}{*}{ Blood and lymphatic system disorders } & Anemia & 1 & 0 & 0 & 0 \\
\hline & Blood and lymphatic system disorders & 1 & 0 & 0 & 0 \\
\hline \multirow[t]{4}{*}{ Metabolism and nutrition disorders } & Anorexia & 2 & 0 & 3 & 0 \\
\hline & Hypoalbuminemia & 0 & 0 & 4 & 0 \\
\hline & Hypokalemia & 0 & 0 & 1 & 0 \\
\hline & Hyponatremia & 0 & 0 & 1 & 0 \\
\hline \multirow[t]{4}{*}{ Gastrointestinal disorders } & Constipation & 0 & 0 & 1 & 0 \\
\hline & Diarrhea & 3 & 0 & 1 & 0 \\
\hline & Mucositis oral & 1 & 0 & 0 & 0 \\
\hline & Nausea & 0 & 0 & 2 & 0 \\
\hline \multirow[t]{6}{*}{ Skin and subcutaneous tissue disorders } & Dry skin & 0 & 0 & 1 & 0 \\
\hline & Pruritus & 1 & 0 & 0 & 0 \\
\hline & Purpura & 0 & 0 & 1 & 0 \\
\hline & Rash acneiform & 4 & 1 & 4 & 0 \\
\hline & Rash maculo-papular & 1 & 0 & 0 & 0 \\
\hline & Skin and subcutaneous tissue disorders & 2 & 0 & 0 & 0 \\
\hline Nervous system disorders & Dysgeusia & 0 & 0 & 1 & 0 \\
\hline \multirow[t]{2}{*}{ Respiratory, thoracic and mediastinal disorders } & Epistaxis & 0 & 0 & 1 & 0 \\
\hline & Pneumonitis & 0 & 0 & 1 & 0 \\
\hline \multirow[t]{3}{*}{ General disorders and administration site conditions } & Fever & 1 & 0 & 0 & 0 \\
\hline & Malaise & 1 & 0 & 0 & 0 \\
\hline & Edema limbs & 1 & 0 & 1 & 0 \\
\hline \multirow[t]{2}{*}{ Renal and urinary disorders } & Hematuria & 0 & 0 & 4 & 0 \\
\hline & Proteinuria & 1 & 0 & 5 & 0 \\
\hline Hepatobiliary disorders & Hepatobiliary disorders & 0 & 1 & 0 & 0 \\
\hline Vascular disorders & Hypertension & 0 & 0 & 2 & 3 \\
\hline Musculoskeletal and connective tissue disorders & Musculoskeletal and connective tissue disorder & 1 & 0 & 0 & 0 \\
\hline \multirow[t]{2}{*}{ Infections and infestations } & Upper respiratory infection & 1 & 0 & 0 & 0 \\
\hline & Urinary tract infection & 2 & 0 & 0 & 0 \\
\hline
\end{tabular}

events of grade 3 or more in group B were hypertension and increases in alanine aminotransferase (Table II).

Compliance to gefitinib (median and range) was 0.95 (range=0.4-1.0) in group A and 0.79 (range=0.55-1.0) in group B. Compliance to bevacizumab was 0.83 (range $=0.6$ 1.0) in the full analysis set.

\section{Discussion}

In the present study, PFS was shorter in the group that received the combination of gefitinib and bevacizumab than in the gefitinib alone group of patients with EGFR mutant non-squamous NSCLC. Previous studies reported that EGFR-
TKI are highly effective in the treatment of mutated-EGFR NSCLC. A phase III study that compared gefitinib with cisplatin plus DTX as the first-line treatment for advanced NSCLC with EGFR mutations (WJTOG3405) showed the superiority of gefitinib over chemotherapy in prolonging PFS.

In order to further prolong PFS and OS, the study compared treatment with erlotinib alone to that with erlotinib and bevacizumab [(erlotinib alone or with bevacizumab as first-line therapy in patients with advanced non-squamous NSCLC harboring EGFR mutations (JO25567)] (14). The findings obtained showed that the addition of bevacizumab to erlotinib significantly prolonged PFS in activating EGFR mutation-positive cases compared to erlotinib alone. 
However, in the present study, PFS showed a tendency to be shorter in the gefitinib plus bevacizumab group (group B) than in the gefitinib alone group (group A). The reason for this unexpected outcome remains unclear. However, the number of cases examined was smaller than originally planned because of poor case collection and early termination, and the number of treatment discontinuation cases, due to adverse events, was high in the gefitinib plus bevacizumab group. However, the reason for early termination was adverse events in 3 cases $(30 \%)$ in the gefitinib alone group. Compliance to gefitinib (median) was 0.79 in the gefitinib plus bevacizumab group and 0.95 in the gefitinib alone group.

Based on the results of the present study, the effectiveness of the combination of bevacizumab and gefitinib for patients with EGFR mutant non-squamous NSCLC was not confirmed. Therefore, there was no basis to proceed to a phase III trial.

\section{Acknowledgements}

The Authors would like to thank all patients and their families who participated in this study, and also thank investigators especially Katsuya Watanabe, Keisuke Aoe, Eisaku Miyauchi, Tatsuo Kato, Toshiyuki Sawa and Hideo Saka. This study was sponsored by the Non-profit Organization (NPO) for Supporting Clinical Research and funded by AstraZeneca plc.

\section{References}

1 World Health Organization: WHO I Top 10 causes of death. Available at: http://www.who.int/gho/mortality_burden_disease /causes_death/top_10/en/. Accessed on 12 December 2018.

2 Hori M, Matsuda T, Shibata A, Katanoda K, Sobue T and Nishimoto H; Japan Cancer Surveillance Research Group: Cancer incidence and incidence rates in Japan in 2009: a study of 32 population-based cancer registries for the Monitoring of Cancer Incidence in Japan (MCIJ) project. Jpn J Clin Oncol 45: 884-891, 2015.

3 Paez JG: EGFR mutations in lung cancer: Correlation with clinical response to gefitinib therapy. Science 304: 1497-1500, 2004.

4 Lynch TJ, Bell DW, Sordella R, Gurubhagavatula S, Okimoto RA, Brannigan BW, Harris PL, Haserlat SM, Supko JG, Haluska FG, Louis DN, Christiani DC, Settleman J and Haber DA: Activating mutations in the epidermal growth factor receptor underlying responsiveness of non-small-cell lung cancer to gefitinib. N Engl J Med 350: 2129-2139, 2004.

5 Pao W, Miller V, Zakowski M, Doherty J, Politi K, Sarkaria I, Singh B, Heelan R, Rusch V, Fulton L, Mardis E, Kupfer D, Wilson R, Kris $\mathrm{M}$ and Varmus H: EGF receptor gene mutations are common in lung cancers from "never smokers" and are associated with sensitivity of tumors to gefitinib and erlotinib. Proc Natl Acad Sci USA 101: 13306-13311, 2004.

6 Shigematsu H and Gazdar AF: Somatic mutations of epidermal growth factor receptor signaling pathway in lung cancers. Int $\mathbf{J}$ Cancer 118: 257-262, 2006.
7 Mok TS, Wu Y-L, Thongprasert S, Yang CH, Chu DT, Saijo N, Sunpaweravong P, Han B, Margono B, Ichinose Y, Nishiwaki Y, Ohe Y, Yang JJ, Chewaskulyong B, Jiang H, Duffield EL, Watkins CL, Armour AA and Fukuoka M: Gefitinib or carboplatin-paclitaxel in pulmonary adenocarcinoma. N Engl J Med 361: 947-957, 2009.

8 Maemondo M, Inoue A, Kobayashi K, Sugawara S, Oizumi S, Isobe H, Gemma A, Harada M, Yoshizawa H, Kinoshita I, Fujita Y, Okinaga S, Hirano H, Yoshimori K, Harada T, Ogura T, Ando M, Miyazawa H, Tanaka T, Saijo Y, Hagiwara K, Morita S and Nukiwa T; North-East Japan Study Group: Gefitinib or chemotherapy for non-small-cell lung cancer with mutated EGFR. N Engl J Med 362: 2380-2388, 2010.

9 Mitsudomi T, Morita S, Yatabe Y, Negoro S, Okamoto I, Tsurutani J, Seto T, Satouchi M, Tada H, Hirashima T, Asami K, Katakami N, Takada M, Yoshioka H, Shibata K, Kudoh S, Shimizu E, Saito $\mathrm{H}$, Toyooka S, Nakagawa $\mathrm{K}$ and Fukuoka M; West Japan Oncology Group: Gefitinib versus cisplatin plus docetaxel in patients with non-small-cell lung cancer harbouring mutations of the epidermal growth factor receptor (WJTOG3405): an open label, randomised phase 3 trial. Lancet Oncol 11: 121-128, 2010.

10 Rosell R, Carcereny E, Gervais R, Vergnenegre A, Massuti B, Felip E, Palmero R, Garcia-Gomez R, Pallares C, Sanchez JM, Porta R, Cobo M, Garrido P, Longo F, Moran T, Insa A, De Marinis F, Corre R, Bover I, Illiano A, Dansin E, de Castro J, Milella M, Reguart N, Altavilla G, Jimenez U, Provencio M, Moreno MA, Terrasa J, Muñoz-Langa J, Valdivia J, Isla D, Domine M, Molinier O, Mazieres J, Baize N, Garcia-Campelo R, Robinet G, Rodriguez-Abreu D, Lopez-Vivanco G, Gebbia V, Ferrera-Delgado L, Bombaron P, Bernabe R, Bearz A, Artal A, Cortesi E, Rolfo C, Sanchez-Ronco M, Drozdowskyj A, Queralt C, de Aguirre I, Ramirez JL, Sanchez JJ, Molina MA, Taron M and Paz-Ares L; Spanish Lung Cancer Group in collaboration with Groupe Français de Pneumo-Cancérologie and Associazione Italiana Oncologia Toracica: Erlotinib versus standard chemotherapy as first-line treatment for European patients with advanced EGFR mutation-positive non-small-cell lung cancer (EURTAC): a multicentre, open-label, randomised phase 3 trial. Lancet Oncol 13: 239-246, 2012.

11 Zhou C, Wu Y-L, Chen G, Feng J, Liu XQ, Wang C, Zhang S, Wang J, Zhou S, Ren S, Lu S, Zhang L, Hu C, Hu C, Luo Y, Chen L, Ye M, Huang J, Zhi X, Zhang Y, Xiu Q, Ma J, Zhang L and You C: Erlotinib versus chemotherapy as first-line treatment for patients with advanced EGFR mutation-positive non-smallcell lung cancer (OPTIMAL, CTONG-0802): a multicentre, open-label, randomised, phase 3 study. Lancet Oncol 12: 735742, 2011.

12 Ichihara E, Ohashi K, Takigawa N, Osawa M, Ogino A, Tanimoto $\mathrm{M}$ and Kiura K: Effects of vandetanib on lung adenocarcinoma cells harboring epidermal growth factor receptor T790M mutation in vivo. Cancer Res 69: 5091-5098, 2009.

13 Cascone T, Herynk MH, Xu L, Du Z, Kadara H, Nilsson MB, Oborn CJ, Park YY, Erez B, Jacoby JJ, Lee JS, Lin HY, Ciardiello F, Herbst RS, Langley RR and Heymach JV: Upregulated stromal EGFR and vascular remodeling in mouse xenograft models of angiogenesis inhibitor-resistant human lung adenocarcinoma. J Clin Invest 121: 1313-1328, 2011.

14 Seto $\mathrm{T}$, Kato $\mathrm{T}$, Nishio $\mathrm{M}$, Goto $\mathrm{K}$, Atagi S, Hosomi $\mathrm{Y}$, Yamamoto N, Hida T, Maemondo M, Nakagawa K, Nagase S, 
Okamoto I, Yamanaka T, Tajima K, Harada R, Fukuoka M and Yamamoto N: Erlotinib alone or with bevacizumab as first-line therapy in patients with advanced non-squamous non-small-cell lung cancer harbouring EGFR mutations (JO25567): an openlabel, randomised, multicentre, phase 2 study. Lancet Oncol 15: 1236-1244, 2014.

15 Herbst RS, Ansari R, Bustin F, Flynn P, Hart L, Otterson GA, Vlahovic G, Soh $\mathrm{CH}$, O'Connor P and Hainsworth J: Efficacy of bevacizumab plus erlotinib versus erlotinib alone in advanced non-small-cell lung cancer after failure of standard first-line chemotherapy (BeTa): a double-blind, placebo-controlled, phase 3 trial. Lancet 377: 1846-1854, 2011.

16 Dingemans AM, de Langen AJ, van den Boogaart V, Marcus JT, Backes WH, Scholtens HT, van Tinteren H, Hoekstra OS, Pruim J, Brans B, Thunnissen FB, Smit EF and Groen HJ: First-line erlotinib and bevacizumab in patients with locally advanced and/or metastatic non-small-cell lung cancer: a phase II study including molecular imaging. Ann Oncol 22: 559-566, 2011.
17 Urata Y, Katakami N, Morita S, Kaji R, Yoshioka H, Seto T, Satouchi M, Iwamoto Y, Kanehara M, Fujimoto D, Ikeda N, Murakami H, Daga H, Oguri T, Goto I, Imamura F, Sugawara S, Saka H, Nogami N, Negoro S, Nakagawa K and Nakanishi Y: Randomized phase III study comparing gefitinib with erlotinib in patients with previously treated advanced lung adenocarcinoma: WJOG 5108L. J Clin Oncol 34: 3248-3257, 2016. 